www.jmscr.igmpublication.org Impact Factor 5.244

Index Copernicus Value: 5.88

ISSN (e)-2347-176x ISSN (p) 2455-0450

crossref DOI: http://dx.doi.org/10.18535/jmscr/v4i5.46

Journal Of Medical Science And Clinical Research

\title{
Mucosal And Skin Reactions In Altered Fractionation Radiotherapy In Locally Advanced Oropharyngeal Carcinoma
}

\author{
Authors \\ Dr Murali. P ${ }^{1}$, Dr Shankar Lal Jakhar ${ }^{2}$, Dr Ramesh Purohit ${ }^{3}$, Dr Rajesh Kumar ${ }^{4}$, \\ Dr Ajay Sharma ${ }^{5}$ \\ 1,3,4 $3^{\text {rd }}$ Year PG Student, Department of Radiotherapy, Atrctri, SPMC, Bikaner, Rajasthan, India \\ ${ }^{2}$ Assistant Professor, Department of Radiation Oncology, Atrctri, SPMC, Bikaner, Rajasthan, India \\ ${ }^{5}$ Senior Professor, Department of Radiation Oncology, Atrctri, SPMC, Bikaner, Rajasthan, India \\ Email: josh.messi19@gmail.com,Contact No:07568934831
}

\begin{abstract}
INTRODUCTION: Mucositis and skin reactions are the most commonly encountered acute toxicities in head and neck irradiation. This is significantly higher in altered fractionation regimens. This study highlights the reactions in two different altered fractionation schedules of radiotherapy.

AIM: to study the acute mucosal and skin reactions in altered fractionation radiotherapy in locally advanced oro-pharyngeal carcinoma.
\end{abstract}

RESULTS: Among the ARM A and ARM B TNM-stage group at presentation was stage III: $40 \%$ and $52 \%$ and stage IV: $60 \%$ and $48 \%$ respectively. Grade III mucositis was encountered in $60 \%$ of patients in arm A compared to $32 \%$ in arm $B(P=<0.01)$. Grade III skin reactions was seen more in arm $A$ than arm $B(52 \%$ Vs $24 \%)(P=<0.01)$.

CONCLUSION: In altered fractionation radiotherapy, it was found that early boosting has an edge over the late boosting in terms of manageable acute toxicities and better compliance.

\section{INTRODUCTION}

Head and neck carcinoma is the most common cancer in India with more than $70 \%$ of the cases presenting in advanced stages. ${ }^{[1]}$ The disease remains confined to the loco-regional site of origin in a significant proportion of patients and the most important cause of death is locoregional recurrence. Various studies have shown concurrent chemoradiation schedules to have better locoregional control (LRC) and improved the overall survival. Accelerated fractionation schedules have been studied effectively in head and neck cancers. It is one method which tends to concentrate on shortening the overall treatment time and thus hampering tumor cell proliferation. ${ }^{[2]}$ Concomitant boost is one of the ways of acceleration wherein a second daily fraction is introduced during any phase of treatment, thus completing the treatment in 5-6 weeks. Mucositis and skin reactions are the most commonly encountered acute toxicity during the course of radiotherapy. This is found to be singinficantly higher in altered fractionation schedules. $^{[3]}$ 


\section{AIM}

To study the acute mucosal and skin reactions in altered fraction radiotherapy in locally advanced oro-pharyngeal carcinoma.

\section{MATERIAL AND METHODS}

Fifty previously untreated patients of oropharyngeal cancer (which include cancer of base of tongue, vallecula and lingual surface of epiglottis, tonsillar region, soft palate and uvula, and oropharyngeal walls), attending the Department of Radiotherapy, Regional Cancer Centre, Bikaner from January 2014 to December 2015 were included in the study fulfilling the following criteria: Biopsy proven cases of squamous cell carcinoma of oropharynx, Stage III, IV, ECOG status 0-1, N-status- upto N2, no commorbidities. Age- $>18-<70$ years. The evaluation consisted of full medical history, physical examination, local examination and endoscopic assessment of site, nature and extent of the disease was done. Work-up consisted of complete hemogram, renal function test, random blood sugar, $\mathrm{X}$ ray chest PA view and $\mathrm{X}$ ray soft tissue neck ( lateral view) and CT scan.

\section{TREAMENT PLANNING AND DELIVERY}

All the patients will be treated in a supine position and properly immobilized by the thermoplastic cast (ORFIT cast).

- Dose prescription and Treatment description:

- ARM A: $45 \mathrm{~Gy} / 25$ fractions/5weeks, $1.8 \mathrm{~Gy} /$ fraction/day, 5 days/week was delivered to the large field comprising the primary disease with extension and the neck nodes. Simultaneously a boost of $22.5 \mathrm{~Gy} / 15$ fractions, $1.5 \mathrm{~Gy} /$ fraction was delivered for the last 15 treatment days to the primary and involved nodal disease. The fractions were delivered 6 hours apart.

- ARM B: $45 \mathrm{~Gy} / 25$ fractions/5weeks, $1.8 \mathrm{~Gy} /$ fraction/day, 5 days/week was delivered to the large field comprising the primary disease with extension and the neck nodes. Simultaneously a boost of $22.5 \mathrm{~Gy} / 15$ fractions, $1.5 \mathrm{~Gy} /$ fraction on alternate day from the $1^{\text {st }}$ day of the treatment for 5 weeks to the primary disease. The fractions were delivered 6 hours apart.

- All patients were planned and treatment was delivered on Cobalt-60 Bhabhatron. Off cord planning was done after delivering $45 \mathrm{~Gy}$.

- The patients in both arms were assessed after every 5 fraction for treatment related acute toxicity.

- The treatment was stopped when the patient developed grade 4 mucosal or skin reactions reactions.

The Biologically Effective Doses (BED) for Tumor control and late adverse effects in each arm will be calculated using the linear quadratic equation. BEDs for both arm is as follows: 78.98 Gy for tumor control and 105.75 Gy for late reacting normal tissues complications. The $\mathbf{E Q D _ { 2 }}$ (equivalent dose for $1.8 \mathrm{~Gy}$ per fraction+ $1.5 \mathrm{~Gy}$ per fraction for bost) for both arms for tumor is $67.5 \mathrm{~Gy}$. Thus the $\mathrm{EQD}_{2}$ is the same in both the treatment arms.

Acute treatment related toxicity assessed and graded using common terminology criteria for adverse events (RTOG). The two arms were compared statistically using SPSS 20.0. 
RESULTS

TABLE 1: SEX DISTRIBUTION

\begin{tabular}{|l|l|l|l|l|}
\hline \multicolumn{2}{|l|}{ ARM A } & \multicolumn{2}{l|}{ ARM B } \\
\hline Sex & No. of patients & Percentage (\%) & No. of patients & Percentage (\%) \\
\hline Male & 24 & 96 & 23 & 92 \\
\hline Female & 1 & 4 & 2 & 8 \\
\hline
\end{tabular}

Table 1 shows the sex distribution of patients included in this study.

TABLE 2: TNM STAGE GROUP

\begin{tabular}{|l|l|l|l|l|}
\hline \multirow{2}{*}{ TNM stage group } & \multicolumn{2}{|l|}{ Study group } & \multicolumn{2}{l|}{ Control group } \\
\cline { 2 - 5 } & No.of patients & Percentage (\%) & No.of patients & Percentage (\%) \\
\hline Stage III & 10 & 40 & 13 & 52 \\
\hline Stage IV & 15 & 60 & 12 & 48 \\
\hline
\end{tabular}

Table 2 shows the distribution of patients according to TNM-stage group.

TABLE 3: TOXICITY PROFILE

\begin{tabular}{|c|c|c|c|c|c|c|c|c|c|c|c|}
\hline \multirow{2}{*}{\begin{tabular}{|l|} 
Toxicity \\
Group \\
\end{tabular}} & \multicolumn{2}{|c|}{ Grade 0} & \multicolumn{2}{|c|}{ Grade I } & \multicolumn{2}{|c|}{ Grade II } & \multicolumn{2}{|c|}{ Grade III } & \multicolumn{2}{|c|}{ Grade IV } & \multirow[b]{2}{*}{ 究 } \\
\hline & $\sum_{\frac{1}{<}}^{\ll}$ & $\sum_{\frac{\alpha}{4}}^{\infty}$ & $\sum_{\frac{1}{4}}^{\ll}$ & $\sum_{\frac{\pi}{4}}^{\infty}$ & $\sum_{\frac{1}{<}}^{\longleftarrow}$ & $\sum_{i}^{\infty}$ & $\sum_{\frac{\alpha}{\alpha}}^{\varangle}$ & $\sum_{\frac{1}{\alpha}}^{\infty}$ & $\sum_{\frac{\alpha}{4}}^{\varangle}$ & $\sum_{\frac{\alpha}{d}}^{\infty}$ & \\
\hline Mucositis & 0 & 0 & 1 & 0 & 7 & 17 & 15 & 8 & 2 & 0 & 50 \\
\hline Skin & 0 & 0 & 2 & 3 & 9 & 16 & 13 & 6 & 1 & 0 & 50 \\
\hline
\end{tabular}

Table 3 shows the incidence of acute toxicity in terms of grade. The $\mathrm{P}$ value of both the skin and mucosal reactions is $<0.01$

\section{DISCUSSION}

The treatment of loco regionally advanced head and neck cancers has undergone a paradigm shift over the past three decades, with management strategies changing from surgery or radiation therapy as single modality to combined modality treatment. A pragmatic approach is to evaluate alternative and viable radiation schedules that provide superior response rates than conventional radiation and yet maintain a favourable toxicity profile, unlike the chemo radiation regimens.

Concomitant boost radiotherapy technique has a strong radiobiological rationale, wherein the boost field is added to the ongoing radiotherapy portals during any phase of radiation to counteract accelerated repopulation of the tumor clonogens. ${ }^{[3,4]}$ This basic premise enhances the chances of tumor control by using a larger dose per fraction in the area of gross tumor volume and at the same time maintains the beneficial effects of acceleration on the tumor and normal tissues. This seemed important not only to optimize the therapeutic ratio, but also the available resources, as this schedule leads to an abbreviation of the overall treatment time from 7 to 5 weeks.

Incidence of disease is more common in male in both arms. As per the literature the male to female ratio of head and neck cancers varies from 3- 
5:1. ${ }^{[5]}$ Among the ARM A and ARM B Among the ARM A and ARM B TNM-stage group at presentation was stage III: $40 \%$ and $52 \%$ and stage IV: $60 \%$ and $48 \%$ respectively.

Mucositis is a major complication of any form of radiation therapy in head and neck cancers. It has a major impact on the overall quality of life during treatment, as well as after treatment. Trotti et al have reviewed the effect of mucositis on patients with head and neck cancers using conventional radiotherapy, accelerated radiotherapy [RT-AF] and chemoradiation $[\mathrm{RT}+\mathrm{CT}]$. The frequency of mucositis was highest in patients with RT-AF, affecting $100 \%$ of patients overall. Patients treated with RT-AF experienced the most severe mucositis, with more than half (57\%) experiencing grade 3-4 mucositis. ${ }^{[6]}$

Alteration of fractionation scheme has mucositis rate of $60 \%$ in various studies. ${ }^{[7]}$ In this study, grade III mucositis was encountered in $60 \%$ of patients in arm A compared to $32 \%$ in arm B $(\mathrm{p}=<0.01)$. Severe skin reaction (grade III) was seen more in arm A than arm B (52\% Vs 24\%) $(\mathrm{p}=<0.01)$. This could be explained by alternate day boost in arm B giving enough time for normal tissue recovery. All patients were started on soda bicarbonate and betadine gargles from first day of the treatment and were treated symptomatically with iv fluids and ryle's tube feeding whenever necessary.

\section{CONCLUSION}

In altered fractionation radiotherapy, it was found that early boosting has an edge over the late boosting in terms of manageable acute toxicities and better compliance. However, larger studies with longer follow-up are needed for standardization a protocol for such boost.

\section{REFERNCES}

1. National Cancer Registry Programme: Consolidated Report of Hospital Based Registries, 1994-1998.
2. Overgaard J, Sand Hansden H, Sapru W et al. Conventional radiotherapy as the primary treatment of squamous cell carcinoma of the head and neck. A randomized multicenter study of 5 versus 6 fractions per week-preliminary report from the DAHANCA 6 and 7 trial. Radiother Oncol 1996;40:S31 .

3. Sasaki T, Sato Y, Sakka M. Cell population kinetics of human solid tumors: a statistical analysis in various histological types. Gann. 1980;71(4):520-9.

4. Thames HD, Jr., Peters LJ, Withers HR, Fletcher GH. Accelerated fractionation vs hyperfractionation: rationales for several treatments per day. Int J Radiat Oncol Biol Phys. 1983;9(2):127-38.

5. Bjordal K, Ahlner-Elmqvist M, Tollesson E, Jensen AB, Razavi D, Maher EJ, et al. Development of a European Organization for Research and Treatment of Cancer (EORTC) questionnaire module to be used in quality of life assessments in head and neck cancer patients. EORTC Quality of Life Study Group. Acta Oncol. 1994;33(8):879-85.

6. Trotti A, Colevas AD, Setser A, Rusch V, Jaques D, Budach V, et al. CTCAE v3.0: development of a comprehensive grading system for the adverse effects of cancer treatment. Semin Radiat Oncol. 2003;13(3):176-81.

7. Valentina Krstevska and Simonida Crvenkova Altered and Conventional Fractionated Radiotherapy in Locoregional Control and Survival of Patients with Squamous Cell Carcinoma of the Larynx, Oropharynx, and Hypopharynx. Croat Med J. 2006; 47(1): 42-52. 